\title{
openheart Decrease in exhaled hydrogen as marker of congestive heart failure
}

\author{
Atsushi Shibata, ${ }^{1}$ Yasuo Sugano, ${ }^{1,2}$ Akito Shimouchi, ${ }^{3,4}$ Tetsuro Yokokawa, ${ }^{1}$ \\ Naoya Jinno, ${ }^{3,4}$ Hideaki Kanzaki, ${ }^{1}$ Keiko Ohta-Ogo, ${ }^{5}$ Yoshihiko Ikeda, ${ }^{5}$ \\ Hideshi Okada, ${ }^{6}$ Takeshi Aiba, ${ }^{1}$ Kengo Kusano, ${ }^{1}$ Mikiyasu Shirai, ${ }^{3}$ \\ Hatsue Ishibashi-Ueda, ${ }^{5}$ Satoshi Yasuda, ${ }^{1}$ Hisao Ogawa, ${ }^{1}$ Toshihisa Anzai ${ }^{1,7}$
}

To cite: Shibata A, Sugano $Y$, Shimouchi A, et al. Decrease in exhaled hydrogen as marker of congestive heart failure. Open Heart 2018;5:e000814. doi:10.1136/ openhrt-2018-000814

Received 6 March 2018 Revised 9 June 2018 Accepted 14 August 2018

Check for updates

(C) Author(s) (or their employer(s)) 2018. Re-use permitted under CC BY-NC. No commercial re-use. See rights and permissions. Published by BMJ.

${ }^{1}$ Department of Cardiovascular Medicine, National Cerebral and Cardiovascular Center, Suita Japan

${ }^{2}$ Division of Cardiovascular Medicine, Keiyu Hospital, Yokohama, Japan

${ }^{3}$ Department of Cardiac Physiology, National Cerebral and Cardiovascular Center, Suita, Japan

${ }^{4}$ College of Life and Health Sciences, Chubu University, Kasugai, Japan

${ }^{5}$ Department of Pathology, National Cerebral and Cardiovascular Center, Suita, Japan

${ }^{6}$ Department of Emergency and Disaster Medicine, Gifu University Graduate School of Medicine, Gifu, Japan

${ }^{7}$ Department of Cardiovascular Medicine, Hokkaido University Graduate School of Medicine, Sapporo, Japan

Correspondence to DrYasuo Sugano; ysugano@ ncvc.go.jp

\section{ABSTRACT}

Objective Hydrogen excretion is thought to be related to systemic antioxidation activity. $\mathrm{H}_{2}$ selectively reduces the hydroxyl radical of free hydrogen $(\bullet \mathrm{OH})$, a highly cytotoxic form of reactive oxygen species, in cultured cells.

Methods We investigated whether exhaled $\mathrm{H}_{2}$ decreased during night sleep, reflected $\bullet \mathrm{OH}$ production and was associated with heart failure severity. We enrolled 108 patients with chronic heart failure (CHF) and 15 control participants without CHF. $\mathrm{H}_{2}$ concentration was measured by gas chromatography in exhaled breath collected before sleep and in the morning after overnight fasting. Overnight change in $\mathrm{H}_{2}$ concentration $\left(\Delta \mathrm{H}_{2}\right)$ was calculated. Mitochondrial morphology evaluated by transmission electron microscopy in endomyocardial biopsies collected from 18 patients with dilated cardiomyopathy.

Results $\Delta \mathrm{H}_{2}$ was significantly lower in patients with CHF compared with controls ( $-4.3 \pm 1.0$ vs $2.0 \pm 2.1 \mathrm{ppm}$, $\mathrm{p}=0.030$ ) and was positively correlated with cardiac index $(\mathrm{Cl} ; \mathrm{r}=-0.285, \mathrm{p}=0.003)$. Patients with $\mathrm{a} \mathrm{H}_{2}<0 \mathrm{ppm}$ had a significantly lower $\mathrm{Cl}$ compared with those who had a $\Delta \mathrm{H}_{2}>0 \mathrm{ppm}\left(2.85 \pm 0.61\right.$ vs $\left.3.24 \pm 0.65 \mathrm{~L} / \mathrm{min} / \mathrm{m}^{2}, \mathrm{p}=0.005\right)$. $\Delta \mathrm{H}_{2}$ was negatively correlated with both the percentage of vacuole-containing mitochondria and indices of cristae remodelling $(r=-0.61, p=0.007)$.

Conclusions Decrease in exhaled $\mathrm{H}_{2}$ during night sleep was associated with CHF severity. $\Delta \mathrm{H}_{2}$ warrants investigation as marker of CHF severity.

\section{INTRODUCTION}

Chronic heart failure (CHF) is an emerging epidemic worldwide with high mortality and rehospitalisation. ${ }^{1}$ Despite the reduced mortality and symptom relief offered by current drugs, the clinical and economic burdens of $\mathrm{CHF}$ remain high. Improved understanding of the pathogenesis and better diagnostic and therapeutic tools would be helpful. ${ }^{2}$ Oxidative stress may play a key role in the pathology of $\mathrm{CHF}^{3}$ Stress resulting from a disturbance in the balance of reactive oxygen species (ROS) and antioxidant defence induces myocyte hypertrophy, cell apoptosis and calcium overload associated with oxidation of membrane phospholipids,

\section{Key questions}

What is already known about this subject?

- Exhaled hydrogen is useful to evaluate intestinal digestive problems; however, the significance of exhaled hydrogen in patients with congestive heart failure has not been described.

What does this study add?

- An overnight decrease in exhaled hydrogen during sleep is associated with a decreased cardiac index in patients with congestive heart failure.

How might this impact on clinical practice?

- Overnight change in exhaled hydrogen concentration could serve as possible marker of heart failure severity.

proteins and DNA. ${ }^{45}$ Accurate measurement of oxidative stress in vivo is challenging, but analysis of exhaled breath analysis has emerged as a non-invasive tool, and it has been evaluated in patients with $\mathrm{CHF}^{6}$ Measurement of exhaled acetone, a volatile component of ketone bodies produced by decarboxylation of acetoacetate, was found to be a useful non-invasive method of evaluating congestive haemodynamics in patients with non-ischaemic CHF.?

Hydrogen $\left(\mathrm{H}_{2}\right)$ is a strong reducing agent in the presence of catalysts such as platinum, nickel and palladium. $\mathrm{H}_{2}$ selectively reduces the hydroxyl radical $(\bullet \mathrm{OH})$, a highly cytotoxic ROS, in cultured cells, ${ }^{8}$ resulting in the production of free hydrogen $\left(\bullet \mathrm{OH}+\mathrm{H}_{2} \rightarrow\right.$ $\mathrm{H}_{2} \mathrm{O}+\mathrm{H}$ ). Exhaled $\mathrm{H}_{2}$ is useful for diagnosing small intestinal bacterial overgrowth and carbohydrate malabsorption and is applied clinically to evaluate intestinal digestive problems. ${ }^{9}{ }^{10} \mathrm{H}_{2}$ produced by enterobacterial fermentation is absorbed into the portal circulation and excreted in the breath. ${ }^{11} \mathrm{H}_{2}$ excretion is thought to be related to systemic antioxidation activity. In patients with CHF, sympathetic activity tends to be greater at night than during the daytime. We speculated 
that increased production of ROS at night increases systemic $\mathrm{H}_{2}$ consumption, including in the intestine, causing a decrease in production of $\mathrm{H}_{2}$ during the night in patients with CHF. The relationship of exhaled $\mathrm{H}_{2}$ and haemodynamic parameters has not been described. The aim of this study was to determine whether the change in exhaled $\mathrm{H}_{2}$ during night sleep $\left(=\Delta \mathrm{H}_{2}\right)$ could be a marker of CHF severity. Mitochondria are damaged by ROS as well as being a source of ROS. ${ }^{12}{ }^{13}$ We also investigated the association of $\Delta \mathrm{H}_{2}$ and the presence of mitochondrial vacuoles in electron micrographs of endomyocardial cells collected from patients with dilated cardiomyopathy (DCM).

\section{METHODS}

\section{Study population}

We prospectively enrolled patients with CHF with elective cardiac catheterisation. Patients were diagnosed with two major criteria or one major CHF criterion in conjunction with two minor Framingham criteria ${ }^{14}$ by at least two independent cardiologists at the National Cerebral and Cardiovascular Centre between December 2014 and September 2015. After excluding those with significant coronary artery disease confirmed coronary angiography, a total of 108 patients were included in the study. Patients with a history of open heart surgery, non-invasive positive pressure ventilation and/or home oxygen therapy, end-stage renal failure, other than the heart failure diet, digestive disorders, or not willing to provide informed consent were also excluded. Fifteen patients without CHF were enrolled as the control group. The control patients were admitted to the same hospital for catheter ablation for arrhythmia during the same period, 14 with paroxysmal supraventricular tachycardia and one with premature ventricular contractions. Demographic, laboratory and echocardiographic data were collected from the patients' medical records at the time of study enrolment.

\section{Study design and assays}

All patients were put on a hospital heart failure diet of 1600 kcal energy with $245 \mathrm{~g}$ carbohydrates, $60 \mathrm{~g}$ protein and 40 $\mathrm{g}$ fat. End expiration breath was collected in a sampling bag (Laboratory for Expiration Biochemistry, Nourishment Metabolism, Nara, Japan) the morning after an overnight fast and before sleep more than 2 hours after eating. Within 48 hours, the collected breath was transferred to a gas-tight glass syringe, and $1 \mathrm{~mL}$ was injected into a gas chromatograph with a semiconductor detector (TRIlyzer mBA-3000, Taiyo, Osaka, Japan) to measure $\mathrm{H}_{2}$. The concentration of the sampled gas was calculated by subtracting ambient air collected in the same bag. The overnight $\Delta \mathrm{H}_{2}$ was calculated by subtracting the exhaled $\mathrm{H}_{2}$ level before sleep from that in the morning. Blood and urine sampling was performed in the early morning. Circulating albumin, uric acid (UA), creatinine, sodium, total bilirubin, C-reactive protein (CRP), high-sensitivity troponin T (hsTnT) and B-type natriuretic peptide (BNP) were assayed by certified methods in the of Clinical Laboratory Department of the National Cerebral and Cardiovascular Centre. The estimated glomerular filtration rate (eGFR) was calculated using the modified isotope dilution mass spectrometry traceable Modification of Diet in Renal Disease (IDMS-MDRD) study equation: eGFR $\left(\mathrm{mL} / \mathrm{min} / 1.73 \mathrm{~m}^{2}\right)=194 \times(\text { serum creatinine })^{-1.094} \times$ $(\text { age })^{-0.287} \times(0.739$ for women $){ }^{15}$

\section{Echocardiography}

Routine echocardiography, including tissue Doppler imaging, was performed to obtain left ventricular ejection fraction (LVEF), left atrial volume index (LAVI), the ratio of early mitral inflow velocity and mitral annular early diastolic velocity $\left(E / e^{\prime}\right)$ and tricuspid regurgitation pressure gradient (TRPG), following the guidelines of the American Society of Echocardiography. ${ }^{16}$ Echocardiography was performed by at least two experienced technicians in a blinded manner.

\section{Cardiac catheterisation}

Coronary angiography was performed in patients with CHF via the radial or femoral artery in a standardised method to exclude the presence of significant coronary stenosis. Right heart catheterisation was performed to obtain haemodynamic parameters including pulmonary capillary wedge pressure (PCWP), pulmonary artery pressure (PAP), right atrial pressure (RAP) and cardiac output $(\mathrm{CO})$ using a 7Fr Swan-Ganz catheter (Goodman, Nagoya, Japan). CO was determined by thermodilution, and the cardiac index (CI) was obtained by dividing $\mathrm{CO}$ by body surface area. Mixed venous oxygen saturation was measured at the same time. All patients in the CHF group with suspected cardiomyopathy underwent endomyocardial biopsy. Three to five pieces of ventricular tissue from different locations of the right ventricle were obtained with disposable biopsy forceps (Technowood, Tokyo, Japan). Tissue samples from 18 patients with a clinical diagnosis of DCM were processed for electron microscopy to evaluate mitochondrial morphology.

\section{Electron microscopy}

Endomyocardial tissue was fixed in $2.5 \%$ glutaraldehyde in $0.1 \mathrm{~mol} / \mathrm{L}$ phosphate buffer at $4^{\circ} \mathrm{C}$ and postfixed in $1 \%$ buffered osmium tetroxide. The specimens were embedded in epoxy resin, and thin sections $(80 \mathrm{~nm})$ were cut and stained with uranyl acetate and lead citrate. The ultrastructure including mitochondria was evaluated in a blinded manner. Over 10 electron micrographs were taken using a Hitachi H-7650 transmission electron microscope (Hitachi High-Technologies, Tokyo, Japan) micrograph. At least 50 mitochondria with evaluable structure of cristae identified in a single micrograph were included in the analysis. The percentage of mitochondria with vacuole was calculated in each study participant (figure 1). 


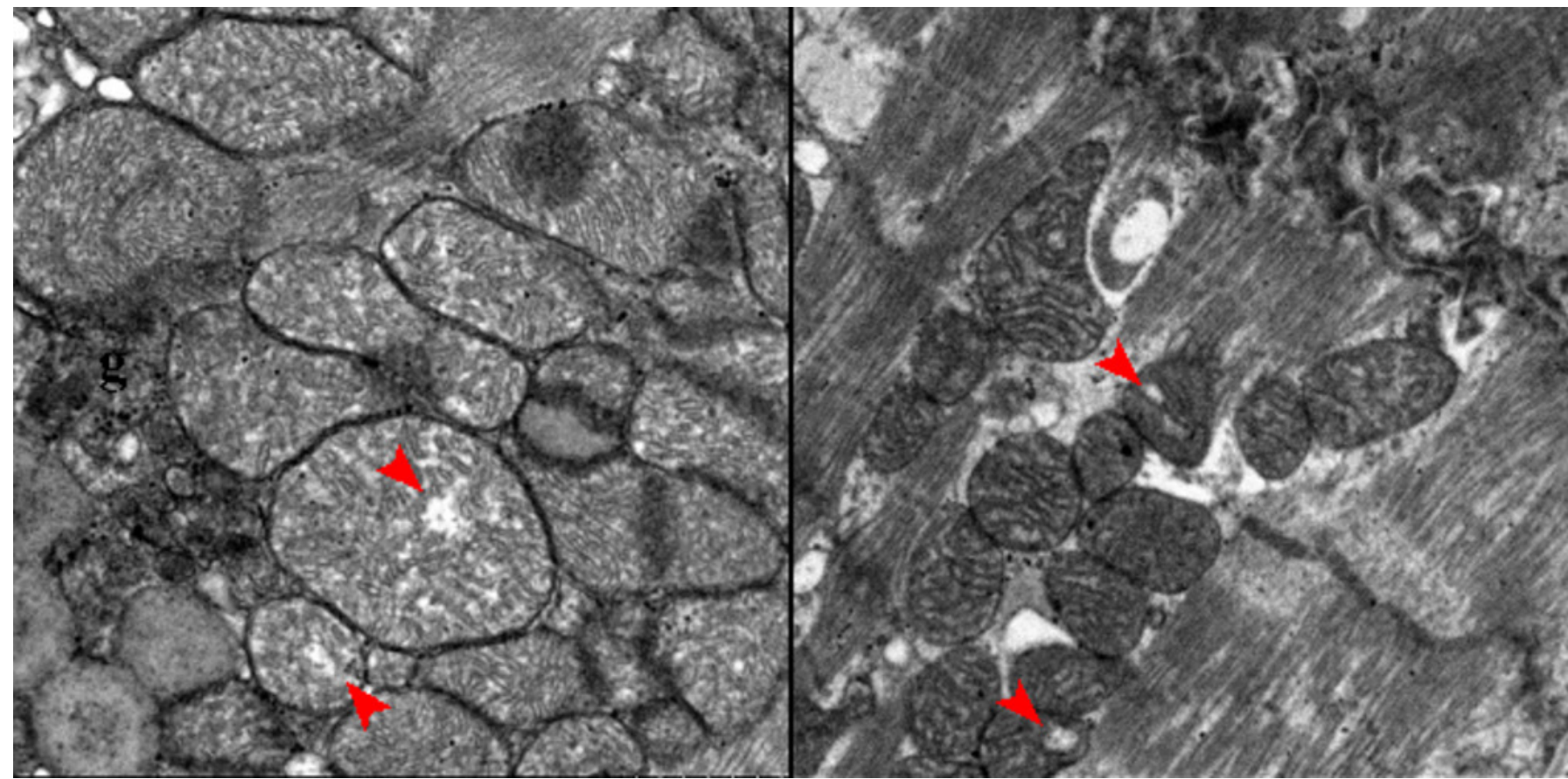

Figure 1 Representative electron micrograph of an endomyocardial specimen biopsied from a patient with dilated cardiomyopathy. Ultrastructural analysis to determine the percentage of mitochondria with vacuoles (arrowheads) was done to evaluate the extent of mitochondrial damage.

\section{Statistical analysis}

Continuous variables were reported as means \pm SD for normally distributed variables or as medians and IQR for non-normally distributed variables. Unpaired t-tests or Wilcoxon-Mann-Whitney tests were used to compare differences of control and CHF group values. Fisher's exact test was used to compare values of categorical variables. Spearman correlation coefficients were calculated for $\Delta \mathrm{H}_{2}$ and each continuous variable. The analysis was performed with JMP V.10 (SAS Institute, Cary, NC, USA). A $p$ value $<0.05$ was considered statistically significant. Lack of statistical significance was reported as non-significant.

\section{RESULTS}

\section{Baseline characteristics}

The baseline demographic and clinical characteristics of the participants are shown in table 1 . The cause of CHF was valvular heart disease in 70 patients $(65 \%)$ and non-ischaemic cardiomyopathy in 38 (35\%). There were no significant differences in the demographic findings in the CHF and control groups except for a higher prevalence of hyperlipidaemia in the patients with CHF. ACE inhibitors, angiotensin II receptor blockers, $\beta$-blockers, mineralocorticoid receptor antagonists and loop diuretics were more frequently used in the CHF group than in the control group. The CHF group had lower eGFR and LVEF and higher plasma BNP levels, LAVI and $E / e^{\prime}$ than the control subjects. Right heart catheter parameters including PCWP and CI were in the normal range in CHF group, indicating that CHF was haemodynamically compensated at the time of the study.

\section{Exhaled $\mathrm{H}_{2}$ concentration}

In $\mathrm{CHF}$ group, the mean exhaled $\mathrm{H}_{2}$ concentration was $7.75 \mathrm{ppm}$ before sleep and $3.43 \mathrm{ppm}$ in the morning (table 2). The exhaled $\mathrm{H}_{2}$ concentration before sleep in the two groups was not significantly different, but in the morning, it was significantly lower in the CHF group than in the control participants. The exhaled $\mathrm{H}_{2}$ concentration in the CHF group was significantly lower in the morning than it was before sleep, but in the control group, it was slightly higher in the morning than before sleep (figure 2). The $\Delta \mathrm{H}_{2}$ was significantly smaller in patients with CHF compared with the control participants $(-4.3 \pm 10.7$ vs $2.0 \pm 7.9 \mathrm{ppm}, \mathrm{p}=0.030$; table 2$)$.

\section{Correlations of $\mathbf{H}_{2}$ concentration and clinical characteristics}

Comparison of $\Delta \mathrm{H}_{2}$, the characteristics measured by echocardiography and cardiac catheterisation revealed that $\Delta \mathrm{H}_{2}$ was positively correlated with $\mathrm{CI} \quad(\mathrm{r}=0.285$, $\mathrm{p}=0.003$ ) (figure 3A) but not with LVEF, $E / e^{\prime}$, TRPG, PCWP, PAP or RAP. $\Delta \mathrm{H}_{2}$ was negatively correlated with blood UA concentration $(\mathrm{r}=-0.200, \mathrm{p}=0.038)$, eGFR $(\mathrm{r}=0.220, \mathrm{p}=0.022), \mathrm{hsTnT}(\mathrm{r}=-0.324, \mathrm{p}=0.001$, figure $3 \mathrm{~B})$ and CRP ( $r=-0.240, p=0.012$, figure $3 \mathrm{C})$. We stratified the patients with CHF by increase or decrease in exhaled $\mathrm{H}_{2}$ concentration during night sleep (table 3 ). There were no significant differences in the age, sex ratio, general clinical data, medications, echocardiography data or laboratory data of the two subgroups. However, the CI was significantly lower in the patients with a decrease in exhaled $\mathrm{H}_{2}$ concentration compared with the $\mathrm{CI}$ in the group with an increase in the exhaled $\mathrm{H}_{2}$ concentration (2.85 \pm 0.61 vs $3.24 \pm 0.65 \mathrm{~L} / \mathrm{min} / \mathrm{m}^{2}, \mathrm{p}=0.005$; figure 4 ). 
Table 1 Baseline characteristics of the patients with chronic heart failure (CHF) and the control patients

\begin{tabular}{|c|c|c|c|}
\hline & \multirow{2}{*}{$\begin{array}{l}\text { CHF } \\
(n=108)\end{array}$} & \multirow{2}{*}{$\begin{array}{l}\text { Control } \\
(n=15)\end{array}$} & \multirow[b]{2}{*}{$P$ values } \\
\hline & & & \\
\hline Male (\%) & 57 (53) & $4(27)$ & 0.058 \\
\hline Age & $66 \pm 15$ & $60 \pm 13$ & 0.187 \\
\hline BMI $\left(\mathrm{kg} / \mathrm{m}^{2}\right)$ & $17.5 \pm 3.0$ & $17.8 \pm 2.6$ & 0.730 \\
\hline \multicolumn{4}{|l|}{ Vital signs } \\
\hline Heart rate (bpm) & $70 \pm 11$ & $75 \pm 14$ & 0.085 \\
\hline Resting systolic BP (mm Hg) & $112 \pm 17$ & $116 \pm 13$ & 0.379 \\
\hline Resting diastolic BP (mm Hg) & $64 \pm 12$ & $69 \pm 13$ & 0.099 \\
\hline \multicolumn{4}{|l|}{ Aetiology } \\
\hline Non-ischaemic cardiomyopathy (\%) & $38(35)$ & $\otimes$ & $凶$ \\
\hline Valvular (\%) & $70(65)$ & $\nabla$ & $凶$ \\
\hline \multicolumn{4}{|l|}{ Coronary risk factors } \\
\hline Diabetes mellitus (\%) & $6(6)$ & $0(0)$ & 0.353 \\
\hline Hypertension (\%) & $52(48)$ & $6(40)$ & 0.557 \\
\hline Hyperlipidaemia (\%) & $34(32)$ & $1(7)$ & 0.046 \\
\hline Ever smoked (\%) & $37(34)$ & $5(33)$ & 0.944 \\
\hline \multicolumn{4}{|l|}{ Baseline use of medications } \\
\hline ACE inhibitor or ARB (\%) & $62(57)$ & $3(20)$ & 0.006 \\
\hline$\beta$-blocker (\%) & $46(43)$ & $2(13)$ & 0.030 \\
\hline Aldosterone receptor antagonist (\%) & $32(30)$ & $0(0)$ & 0.014 \\
\hline Loop diuretic (\%) & $48(44)$ & $0(0)$ & $<0.001$ \\
\hline \multicolumn{4}{|l|}{ Laboratory data } \\
\hline Alb (g/dL) & $4.2 \pm 0.4$ & $4.4 \pm 0.2$ & 0.043 \\
\hline $\mathrm{UA}(\mathrm{mg} / \mathrm{dL})$ & $6.0 \pm 1.7$ & $4.4 \pm 1.3$ & $<0.001$ \\
\hline eGFR $\left(\mathrm{mL} / \mathrm{min} / 1.73 \mathrm{~m}^{2}\right)$ & $65.5(53.5-73.5)$ & 74.5 (64.6-98.5) & 0.028 \\
\hline Sodium (mEq/L) & $140.7 \pm 3.5$ & $141.3 \pm 1.4$ & 0.511 \\
\hline T-bil (mg/dL) & $0.8 \pm 0.5$ & $0.7 \pm 0.3$ & 0.282 \\
\hline $\mathrm{CRP}(\mathrm{mg} / \mathrm{dL})$ & $0.20 \pm 0.45$ & $0.03 \pm 0.02$ & 0.157 \\
\hline hsTnT (ng/mL) & $0.012(0.006-0.020)$ & $\otimes$ & $凶$ \\
\hline $\mathrm{BNP}(\mathrm{pg} / \mathrm{mL})$ & $175.4(73.8-287.3)$ & $25.5(11.6-37.0)$ & 0.001 \\
\hline \multicolumn{4}{|l|}{ Echocardiogram } \\
\hline LV ejection fraction (\%) & $49 \pm 16$ & $60 \pm 2$ & 0.013 \\
\hline LA volume index $\left(\mathrm{mL} / \mathrm{m}^{2}\right)$ & $62(41-82)$ & $35(27-41)$ & 0.039 \\
\hline E/e' ratio & $14.0 \pm 6.3$ & $7.9 \pm 2.3$ & $<0.001$ \\
\hline TRPG (mm Hg) & $28.9 \pm 10.1$ & $21.0 \pm 7.1$ & 0.014 \\
\hline \multicolumn{4}{|l|}{ Haemodynamic data } \\
\hline Mean PCWP (mm Hg) & $11.5 \pm 6.0$ & $\nabla$ & $\nabla$ \\
\hline Mean PAP (mm Hg) & $19.0 \pm 6.4$ & $\otimes$ & $凶$ \\
\hline Mean RAP $(\mathrm{mm} \mathrm{Hg})$ & $4.3 \pm 3.0$ & $\nabla$ & $\nabla$ \\
\hline $\mathrm{Cl}\left(\mathrm{L} / \mathrm{min} / \mathrm{m}^{2}\right)$ & $2.96 \pm 0.6$ & $\nabla$ & $\nabla$ \\
\hline $\mathrm{SvO}_{2}(\%)$ & $68.7 \pm 5.9$ & $\otimes$ & $\otimes$ \\
\hline
\end{tabular}

Values are means $\pm \mathrm{SD}$, median $(\mathrm{IQR})$, or $\mathrm{n}(\%)$.

Alb, albumin; ARB, angiotensin receptor blocker; BMI, body mass index; BNP, B-type natriuretic peptide; BP, blood pressure; Cl, cardiac index; CRP, C-reactive protein; E/e', ratio of early transmitral velocity to tissue Doppler mitral annular velocity during early diastole; eGFR, estimated glomerular filtration rate; hsTnT, high-sensitivity troponin T; LA, left atrial; LV, left ventricular; PAP, pulmonary artery pressure; PCWP, pulmonary capillary wedge pressure; RAP, right atrial pressure; $\mathrm{SvO}_{2}$, mixed venous oxygen saturation; T-bil, total bilirubin; TRPG, tricuspid regurgitation pressure gradient; UA, uric acid. 
Table 2 Exhaled hydrogen in patients with chronic heart failure (CHF) and controls

\begin{tabular}{|c|c|c|c|}
\hline & CHF & Control & P values \\
\hline & $(n=108)$ & $(n=15)$ & $\begin{array}{l}\text { (CHF vs } \\
\text { control) }\end{array}$ \\
\hline \multicolumn{4}{|l|}{ Hydrogen $\left(\mathrm{H}_{2}\right)(\mathrm{ppm})$} \\
\hline Before sleep (1) & $7.75 \pm 11.9$ & $6.45 \pm 6.6$ & 0.682 \\
\hline Morning (2) & $3.43 \pm 4.4$ & $8.47 \pm 12.5$ & 0.003 \\
\hline$P$ values ((1) vs (2)) & $<0.001$ & 0.596 & \\
\hline$\Delta \mathrm{H}_{2}((2)-(1))$ & $-4.32 \pm 10.7$ & $2.02 \pm 7.9$ & 0.030 \\
\hline
\end{tabular}

Values are means \pm SD.

\section{Mitochondrial morphology}

Evaluation of the electron micrographs of the endomyocardial biopsy tissue obtained from 18 patients revealed a significant positive correlation of $\Delta \mathrm{H}_{2}$ and percentage of mitochondria with vacuoles $(\mathrm{r}=0.61, \mathrm{p}=0.007$; figure 5$)$, suggesting that the overnight decrease in exhaled $\mathrm{H}_{2}$ concentration was related to mitochondrial damage.

\section{DISCUSSION}

The main study findings are the significant overnight decrease in exhaled $\mathrm{H}_{2}$ concentration in patients with CHF compared with the control participants and the inverse correlation of the decrease with CI. Electron microscopy of myocardial tissue suggested that mitochondrial damage might have been associated with $\mathrm{H}_{2}$ consumption during the night-time hours. To the best of our knowledge, this is the first study to demonstrate the significance of a decrease in exhaled $\mathrm{H}_{2}$ concentration in patients with CHF. The cause of the change in exhaled hydrogen concentration during the night has not been determined. $\mathrm{H}_{2}$ included in exhaled air is thought to be produced by anaerobic fermentation in the lower gastrointestinal tract. The significance of

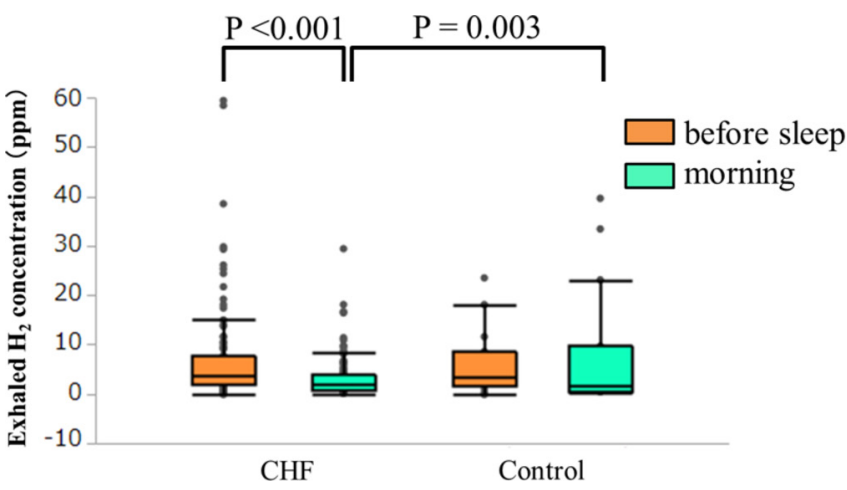

Figure 2 Assay of exhaled hydrogen $\left(\mathrm{H}_{2}\right)$ in patients with chronic heart failure (CHF) and control participants. No significant differences in exhaled $\mathrm{H}_{2}$ concentration were observed before sleep (orange bars). The morning $\mathrm{H}_{2}$ concentration was lower in patients with $\mathrm{CHF}$ than in control group (green bars; $p=0.003$ ). A significant overnight decrease in exhaled $\mathrm{H}_{2}$ concentration was observed in $\mathrm{CHF}$ group $(p<0.001)$.

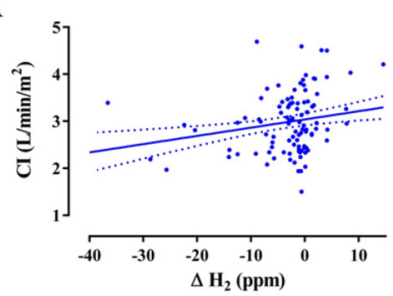

C

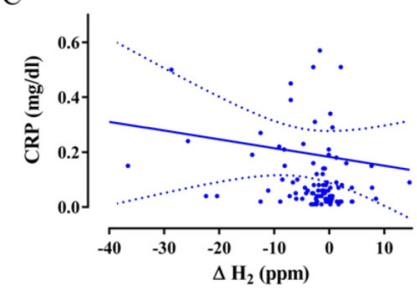

B

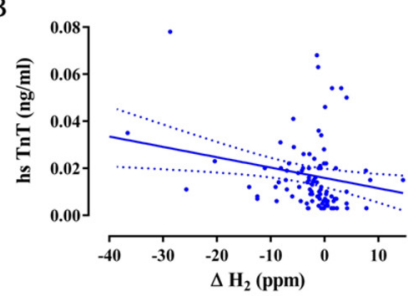

Figure 3 Correlation of change in $\mathrm{H}_{2}$ concentration $\left(\nabla \mathrm{H}_{2}\right)$ haemodynamics or laboratory parameters. (A) $\Delta \mathrm{H}_{2}$ was positively correlated with cardiac index $(\mathrm{Cl} ; \mathrm{r}=0.285$, $\mathrm{p}=0.003)$. (B) $\Delta \mathrm{H}_{2}$ was negatively correlated with highsensitivity troponin $\mathrm{T}$ (hsTnT; $r=-0.324, p=0.001$ ). (C) $\Delta \mathrm{H}_{2}$ was negatively correlated with $\mathrm{C}$-reactive protein (CRP; $r=-0.240, p=0.012$ ).

hydrogen production by enteral anaerobic fermentation is not clear, but a previous study in a rat hepatic ischaemia-reperfusion model suggested an antioxidative effect. ${ }^{17}$ Altered intestinal function and changes of the enterobacterial flora have been reported in patients with CHF. ${ }^{18}$ Given the available evidence and the presence of autonomic hyperactivity at night in patients with CHF, it is possible that hydrogen derived from enteral anaerobic fermentation is consumed at night by antioxidant activity, resulting in a decrease in the exhaled hydrogen concentration in patients with CHF in the morning. At night, before sleeping, the exhaled $\mathrm{H}_{2}$ concentration in patients with CHF and in control participants was comparable, suggesting that some homeostatic mechanism may increase enteric $\mathrm{H}_{2}$ production in the daytime to maintain the body balance in CHF.

In this study, echocardiography and right heart catheterisation were used to evaluate the relationship between $\Delta \mathrm{H}_{2}$ and heart function in the patients with CHF. $\Delta \mathrm{H}_{2}$ was significantly correlated with $\mathrm{CI}$ but not with echocardiographic parameters or haemodynamic indices of volume overload such as PCWP, PAP and RAP. The association of an overnight decrease in exhaled $\mathrm{H}_{2}$ concentration with a lower CI can be explained in part by an increase in ROS accompanied by a decrease in tissue perfusion. A decreased CI as a consequence of a haemodynamic deterioration in patients with CHF may induce intestinal motility disturbance that results in altered enterobacterial flora and decrease in exhaled $\mathrm{H}_{2} \cdot{ }^{20}$

In this study, electron micrographs of tissue from patients with DCM confirmed a significant correlation between $\Delta \mathrm{H}_{2}$ and the percentage of mitochondria having vacuoles. Mitochondrial vacuoles reflect abnormal cristae patterns because of mitochondrial 
Table 3 Baseline characteristics of study patients and overnight change in exhaled $\mathrm{H} 2(\Delta \mathrm{H} 2)$

\begin{tabular}{|c|c|c|c|}
\hline & \multirow{2}{*}{$\begin{array}{l}\text { Decrease } \mathrm{H}_{2} \\
\left(\Delta \mathrm{H}_{2}<0 \mathrm{ppm}\right)\end{array}$} & \multirow{2}{*}{$\begin{array}{l}\text { Increase } H_{2} \\
\left(\Delta \mathrm{H}_{2} \geq 0 \mathrm{ppm}\right)\end{array}$} & \multirow[b]{3}{*}{$P$ values } \\
\hline & & & \\
\hline & $(n=78)$ & $(n=30)$ & \\
\hline Age & $67 \pm 14$ & $63 \pm 16$ & 0.198 \\
\hline \multicolumn{4}{|l|}{ General examination } \\
\hline Heart rate (bpm) & $69 \pm 10$ & $71 \pm 14$ & 0.337 \\
\hline Resting systolic BP (mm Hg) & $112 \pm 17$ & $112 \pm 15$ & 0.910 \\
\hline Resting diastolic BP (mm Hg) & $64 \pm 13$ & $63 \pm 10$ & 0.570 \\
\hline \multicolumn{4}{|l|}{ Laboratory data } \\
\hline Alb $(g / d L)$ & $4.2 \pm 0.4$ & $4.3 \pm 0.3$ & 0.203 \\
\hline T-bil (mg/dL) & $0.8 \pm 0.4$ & $0.9 \pm 0.6$ & 0.181 \\
\hline $\mathrm{CRP}(\mathrm{mg} / \mathrm{dL})$ & $0.24 \pm 0.52$ & $0.09 \pm 0.11$ & 0.120 \\
\hline hsTnT (ng/mL) & $0.014(0.008-0.022)$ & $0.007(0.004-0.018)$ & 0.284 \\
\hline $\mathrm{BNP}(\mathrm{pg} / \mathrm{mL})$ & $148(74-301)$ & $186(100-275)$ & 0.601 \\
\hline \multicolumn{4}{|l|}{ Echocardiogram } \\
\hline LV ejection fraction (\%) & $48 \pm 15$ & $49 \pm 18$ & 0.765 \\
\hline LA volume index $\left(\mathrm{mL} / \mathrm{m}^{2}\right)$ & $62(39-88)$ & $64(49-83)$ & 0.367 \\
\hline Ele' ratio & $13.6 \pm 6.0$ & $15.0 \pm 6.9$ & 0.342 \\
\hline $\mathrm{SvO}_{2}(\%)$ & $68.7 \pm 6.2$ & $68.6 \pm 4.8$ & 0.962 \\
\hline
\end{tabular}

Values are means $\pm \mathrm{SD}$, median (IQR), or $\mathrm{n}(\%)$.

Alb, albumin; BMI, body mass index; BNP, B-type natriuretic peptide; BP, blood pressure; Cl, cardiac index; CRP, C-reactive protein; E/e', ratio of early transmitral velocity to tissue Doppler mitral annular velocity during early diastole; eGFR, estimated glomerular filtration rate; hsTnT, high-sensitivity troponin T; LA, left atrial; LV, left ventricular; PAP, pulmonary artery pressure; PCWP, pulmonary capillary wedge pressure; RAP, right atrial pressure; $\mathrm{SvO}_{2}$, mixed venous oxygen saturation; T-bil, total bilirubin; TRPG, tricuspid regurgitation pressure gradient; UA, uric acid.

DNA damage by ROS and impaired mitochondrial quality. ${ }^{13} 21$ The results indicate that increased ROS production may result in phenotypically damaged mitochondria in patients with CHF that are associated with increased overnight consumption of $\mathrm{H}_{2}$. Antioxidants, including $\mathrm{H}_{2}$, may ameliorate myocardial failure. Inhalation of $\mathrm{H}_{2}$ gas was found to attenuate the deleterious changes induced by intermittent hypoxia in cardiomyopathic hamsters. ${ }^{22}$ Inhalation of $\mathrm{H}_{2}$ gas was also found to protect the heart and to reduce LV remodelling after ischaemia-reperfusion injury. ${ }^{23}$ These results indirectly support our finding that $\mathrm{H}_{2}$ might reduce ROS in patients with CHF.
Breath analysis has the advantages of being non-invasive and easy to perform and repeat, which favour use as a disease marker. We recently reported that exhaled acetone may be useful as a biomarker of pulmonary congestion in patients with CHF comparable with blood BNP. ${ }^{7}$ Overnight decrease in exhaled $\mathrm{H}_{2}$ may serve as surrogate of CI and ROS production in patients with $\mathrm{CHF}$. Although exhaled $\mathrm{H}_{2}$ derives from anaerobic metabolism in the lower gastrointestinal tract that is easily affected by variety of factors such as diet, it may be a candidate marker in CHF. Additional research with long-term follow-up is warranted, as biomarkers that can estimate the severity of CHF are needed. ${ }^{24}$ 


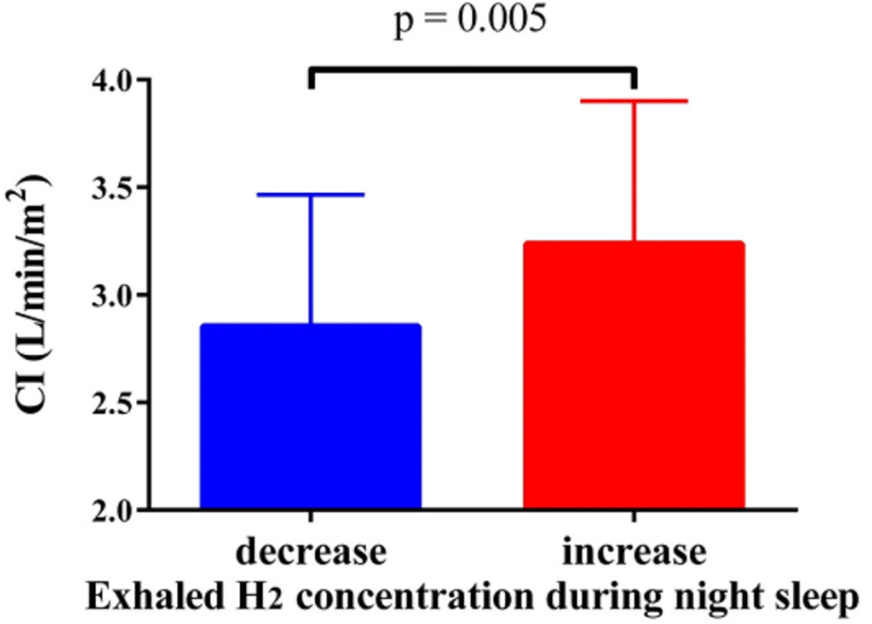

Figure 4 Comparison of cardiac index $(\mathrm{Cl})$ in patients with overnight decreased exhaled hydrogen $\left(\mathrm{H}_{2}\right)$ concentration and increased exhaled $\mathrm{H}_{2}$ concentration. $\mathrm{Cl}$ was significantly lower in the decreased exhaled $\mathrm{H}_{2}$ than in the other group $(2.85 \pm 0.61$ vs $3.24 \pm 0.65 \mathrm{~L} / \mathrm{min} / \mathrm{m} 2, \mathrm{p}=0.005)$. Data are means \pm SD.

\section{Study limitations}

First, this was a monocentre study that included a small number of cases. Although the pathological examination was conducted in a blinded manner, to improve objectivity, multicentre prospective trials would be helpful. Second, $65 \%$ of the patients had valvular heart disease and most were in need of valve surgery. Consequently, the study population may not be representative of all patients with CHF. Third, the use of antioxidant drugs was not considered. Angiotensin II receptor blockers, $\beta$-adrenoceptor blockers and statins, which were used by most of the patients in this study, have shown antioxidant activity, ${ }^{25-27}$ and may have influenced ROS production. Finally, since the reaction that $\mathrm{H}_{2}$ selectively reduces the

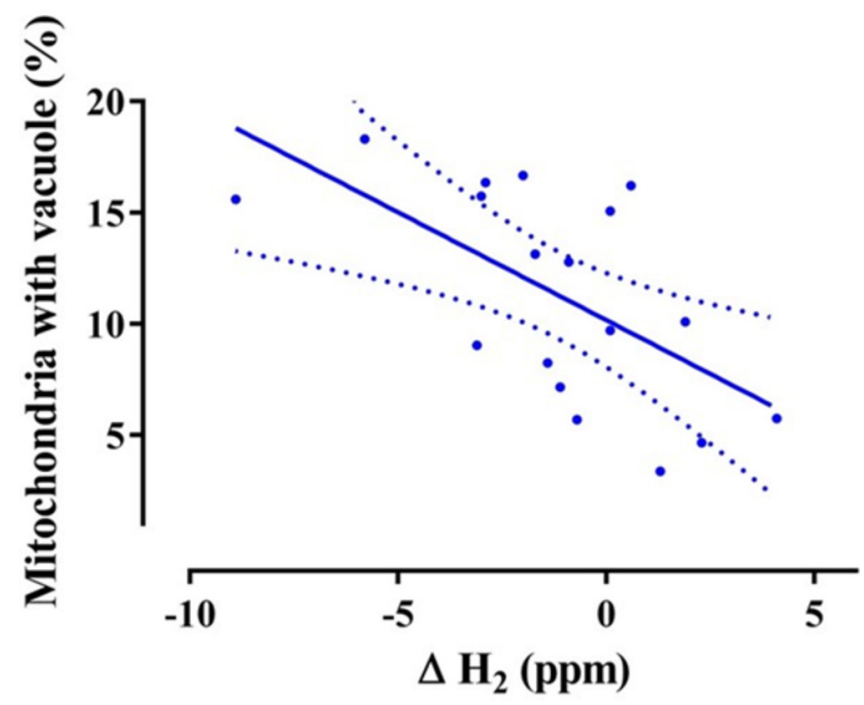

Figure 5 The percentage of mitochondria in endomyocardial tissue cells with vacuoles and overnight change in $\mathrm{H}_{2}$ concentration had a significant positive correlation $(r=-0.61, p=0.007)$. hydroxyl radical $(\bullet \mathrm{OH})$ has not been demonstrated in vivo, basic experiments to prove this reaction in vivo are also necessary.

\section{CONCLUSIONS}

In conclusion, this study demonstrated that an overnight decrease in exhaled $\mathrm{H}_{2}$ during sleep was associated with a decreased $\mathrm{CI}$ in patients with $\mathrm{CHF}$. $\mathrm{H}_{2}$ may be a marker of $\mathrm{CHF}$.

Contributors AShib, YS and AShim conceived the present idea. AShib and YS wrote the manuscript. TY collected samples. HK and TAi provided and cared for study patients. $\mathrm{NJ}$ analysed gas samples. $\mathrm{KOO}$ and $\mathrm{Yl}$ analysed biopsy specimens. HOK performed statistics. KK, MS, HIU, SY, HOg and TAn critically reviewed the study proposal. All authors discussed the results and contributed to the final manuscript.

Funding This work was supported by a Grant-in-Aid for Scientific Research from the Japanese Society for the Promotion of Science Kakenhi Grant number 2646098 to YS; number 15K19401 to TY; Kakenhi Grant number 2511176 to NJ; Kakenhi Grant number 26253037 to AShim; the Intramural Research Fund of the National Cerebral and Cardiovascular Research Center 25-2-1 to AShim; and the Center of Innovation, Science and Technology based Radical Innovation and Entrepreneurship Program, Japan, to AShim.

Competing interests None declared.

Patient consent Obtained.

Ethics approval The study protocol was approved by the Research Ethics Review Committee of the National Cerebral and Cardiovascular Center (number M26-109) and was conducted following the ethical guidelines of the Helsinki Declaration.

Provenance and peer review Not commissioned; internally peer reviewed.

Data sharing statement There are no additional data available for this paper.

Open access This is an open access article distributed in accordance with the Creative Commons Attribution Non Commercial (CC BY-NC 4.0) license, which permits others to distribute, remix, adapt, build upon this work non-commercially, and license their derivative works on different terms, provided the original work is properly cited, appropriate credit is given, any changes made indicated, and the use is non-commercial. See: http://creativecommons.org/licenses/by-nc/4.0/

\section{REFERENCES}

1. Roger VL. Epidemiology of heart failure. Circ Res 2013;113:646-59.

2. Yancy CW, Jessup M, Bozkurt B, et al. 2013 ACCF/AHA guideline for the management of heart failure: executive summary: a report of the American College of Cardiology Foundation/American Heart Association Task Force on practice guidelines. Circulation 2013;128:1810-52.

3. Braunwald E. Biomarkers in heart failure. $N$ Engl J Med 2008;358:2148-59.

4. Spinale FG, Coker ML, Thomas CV, et al. Time-dependent changes in matrix metalloproteinase activity and expression during the progression of congestive heart failure: relation to ventricular and myocyte function. Circ Res 1998;82:482-95.

5. McCord JM. Oxygen-derived free radicals in postischemic tissue injury. N Engl J Med 1985;312:159-63.

6. Marcondes-Braga FG, Batista GL, Bacal F, et al. Exhaled Breath Analysis in Heart Failure. Curr Heart Fail Rep 2016;13:166-71.

7. Yokokawa T, Sugano Y, Shimouchi A, et al. Exhaled Acetone Concentration Is Related to Hemodynamic Severity in Patients With Non-Ischemic Chronic Heart Failure. Circ J 2016;80:1178-86.

8. Ohsawa I, Ishikawa M, Takahashi K, et al. Hydrogen acts as a therapeutic antioxidant by selectively reducing cytotoxic oxygen radicals. Nat Med 2007;13:688-94.

9. Korth H, Müller I, Erckenbrecht JF, et al. Breath hydrogen as a test for gastrointestinal transit. Hepatogastroenterology 1984;31:282-4.

10. Rana SV, Malik A. Hydrogen breath tests in gastrointestinal diseases. Indian J Clin Biochem 2014;29:398-405.

11. Perman JA. Clinical application of breath hydrogen measurements. Can J Physiol Pharmacol 1991;69:111-5.

12. Ide $\mathrm{T}$, Tsutsui $\mathrm{H}$, Hayashidani $\mathrm{S}$, et al. Mitochondrial DNA damage and dysfunction associated with oxidative stress in failing hearts after myocardial infarction. Circ Res 2001;88:529-35. 
13. Tsutsui H, Kinugawa S, Matsushima S. Mitochondrial oxidative stress and dysfunction in myocardial remodelling. Cardiovasc Res 2009;81:449-56.

14. McKee PA, Castelli WP, McNamara PM, et al. The natural history of congestive heart failure: the Framingham study. N Engl J Med 1971;285:1441-6.

15. Matsuo S, Imai E, Collaborators developing the Japanese equation for estimated GFR. Revised equations for estimated GFR from serum creatinine in Japan. Am J Kidney Dis 2009;53:982-92.

16. Chamber Quantification Writing GroupAmerican Society of Echocardiography's Guidelines and Standards CommitteeEuropean Association of Echocardiography. Recommendations for chamber quantification: a report from the American Society of Echocardiography's Guidelines and Standards Committee and the Chamber Quantification Writing Group, developed in conjunction with the European Association of Echocardiography, a branch of the European Society of Cardiology. J Am Soc Echocardiogr 2005; $18: 1440-63$

17. Nishimura N, Tanabe H, Sasaki Y, et al. Pectin and highamylose maize starch increase caecal hydrogen production and relieve hepatic ischaemia-reperfusion injury in rats. $\mathrm{Br} J$ Nutr 2012;107:485-92.

18. Rauchhaus M, Anker SD. Plasma concentrations of bacterial lipopolysaccharide: a marker of infection or inflammation? J Am Coll Cardiol 2000;36:656-7.

19. Sandek A, Bauditz J, Swidsinski A, et al. Altered intestinal function in patients with chronic heart failure. J Am Coll Cardiol 2007:50:1561-9.
20. Fruhwald $\mathrm{S}$, Holzer $\mathrm{P}$, Metzler $\mathrm{H}$. Intestinal motility disturbances in intensive care patients pathogenesis and clinical impact. Intensive Care Med 2007;33:36-44.

21. Arbustini E, Diegoli M, Fasani R, et al. Mitochondrial DNA mutations and mitochondrial abnormalities in dilated cardiomyopathy. $A m \mathrm{~J}$ Pathol 1998;153:1501-10.

22. Kato $R$, Nomura $A$, Sakamoto $A$, et al. Hydrogen gas attenuates embryonic gene expression and prevents left ventricular remodeling induced by intermittent hypoxia in cardiomyopathic hamsters. Am J Physiol Heart Circ Physiol 2014;307:H1626-33.

23. Hayashida K, Sano M, Ohsawa I, et al. Inhalation of hydrogen gas reduces infarct size in the rat model of myocardial ischemiareperfusion injury. Biochem Biophys Res Commun 2008;373:30-5.

24. Tang WH, Francis GS, et al. National Academy of Clinical Biochemistry Laboratory Medicine. National Academy of Clinical Biochemistry Laboratory Medicine practice guidelines: Clinical utilization of cardiac biomarker testing in heart failure. Circulation 2007:116:e99-109.

25. Berry C, Anderson N, Kirk AJ, et al. Renin angiotensin system inhibition is associated with reduced free radical concentrations in arteries of patients with coronary heart disease. Heart 2001;86:217-20.

26. Asanuma H, Minamino T, Sanada S, et al. Beta-adrenoceptor blocker carvedilol provides cardioprotection via an adenosine-dependent mechanism in ischemic canine hearts. Circulation 2004;109:2773-9.

27. Mason RP, Walter MF, Trumbore MW, et al. Membrane antioxidant effects of the charged dihydropyridine calcium antagonist amlodipine. J Mol Cell Cardiol 1999;31:275-81. 